\title{
Evaluations of Scavenge Port Designs for a Boosted Uniflow Scavenged Direct Injection Gasoline (BUSDIG) Engine by 3D CFD Simulations
}

\author{
Author, co-author (Do NOT enter this information. It will be pulled from participant tab in \\ MyTechZone) \\ Affiliation (Do NOT enter this information. It will be pulled from participant tab in MyTechZone)
}

Copyright $\odot 2016$ SAE International

\begin{abstract}
The 2-stroke engine has great potential for aggressive engine downsizing due to its double firing frequency which allows lower indicated mean effective pressure (IMEP) and peak in-cylinder pressure with the same output toque compared to the 4-stroke engine. With the aid of new engine technologies, e.g. direct injection, boost and variable valve trains, the drawbacks of traditional 2-stroke engine, e.g. low durability and high emissions, can be resolved in a Boosted Uniflow Scavenged Direct Injection Gasoline (BUSDIG) engine. Compared to the loop-flow or cross-flow engines, the BUSDIG engine, where intake ports are integrated to the cylinder liner and controlled by the movement of piston top while exhaust valves are placed in the cylinder head, can achieve excellent scavenging performance and be operated with high boost.
\end{abstract}

In order to fulfil the potential of the BUSDIG engine, various scavenge ports were designed with different scavenge port number (SPN), Axis Inclination Angle (AIA) and Swirl Orientation Angle (SOA), and their effects were evaluated by three dimensional (3D) computational fluid dynamics (CFD) under different intake pressures and engine speeds. The scavenging process was analyzed by its delivery ratio (DR), trapping efficiency (TE), scavenging efficiency (SE) and charging efficiency (CE). In addition, the in-cylinder flow motions, which play important roles in controlling the charge mixing and combustion process, were studied for different scavenge port designs. Finally, the vertical position of scavenge ports, which determines the scavenge port opening (SPO) timing, the scavenge port height $(\mathrm{SPH})$, and the exhaust valve opening (EVO) timings were varied to investigate their impacts on the scavenging performance and in-cylinder flow motions.

\section{Introduction}

The stringent pollutant emission regulations and higher engine efficiency requirements are driving the development of internal combustion engine technologies. The engine down-sizing technology has shown the great potential to reduce the vehicle fuel consumption. However, the application of down-sizing to the four-stroke gasoline engine is limited by the significantly increased peak cylinder pressure, knocking combustion and associated thermal and mechanical load. Compared to the 4-stroke engine, a 2-stroke engine doubles firing frequency and thus allows lower IMEP and peak in-cylinder pressure with the same output toque. In addition, the higher power-to-weight ratio and more compact dimension make the 2-stroke engine naturally suitable for aggressive engine down-sizing to increase the power density and improve fuel economy.

However, the traditional design of the 2-stroke engine shows high fuel consumption and pollutant emissions because of the charge (air/fuel) short-circuiting. The application of direct injection and advanced scavenging method would significantly improve the performance of 2-stroke engines. The direct injection after exhaust valve closing avoids the fuel short-circuiting, which in turn lowers the fuel consumption and pollutant emissions dramatically. In addition, the fuel consumption of the 2-stroke engine can be further improved with lean/stratified charge achieved by direct injection [14] and advanced combustion concept [5-10], e.g. homogeneous charge compression ignition (HCCI), controlled auto-ignition (CAI), partially premixed combustion (PPC) and reactivity-controlled compression ignition (RCCI).

The scavenging process is essential for a 2-stroke engine, as it scavenges the burnt gases from the previous cycle out of the cylinder and replaces with the fresh charge for the next cycle. Because of the long overlapping period of intake and exhaust process in the 2-stroke engine, one of the key issues is the short-circuiting phenomenon, in which some of the intake fresh mixture can flow directly into the exhaust port during the scavenging process [11]. The optical measurement $[12,13]$ and computational fluid dynamic (CFD) simulations [14-18] of the uniflow 2-stroke engine proved the superior scavenging performance of uniflow. The intake ports in a uniflow engine are integrated into the cylinder liner and controlled by the movement of the piston top while exhaust valves are placed in the cylinder head. This layout also enables the application of variable valve timing (VVT) technology to adjust the exhaust valve timing and control the hot residual gas and scavenging process under different boost pressures at various engine speeds. The uniflow engine can also minimize the bore distortion caused by uneven thermal loading in the conventional ported 2-stroke engine with cold intake port on one side and hot exhaust port on the other.

The 2-stroke uniflow engines have been widely used in large marine diesel engines [13-15] and recently researched for potential applications to passenger cars $[3,4,7,10,16,18-21]$. In this project, a novel 2-stroke Boosted Uniflow Scavenged Direct Injection Gasoline (BUSDIG) engine was proposed to achieve aggressive engine downsizing. In order to maximize the scavenge performance and optimize the in-cylinder flow motion, the 3D CFD simulations 
were adopted in this study to evaluate different scavenge port designs for the proposed BUSDIG engine. A $0.5 \mathrm{~L}$ single cylinder engine with scavenge ports integrated to the cylinder liner was adopted in this study. Several important design parameters, e.g. scavenge port number (SPN), axis inclination angle (AIA), swirl orientation angle (SOA), scavenge port opening (SPO) timing, scavenge port height $(\mathrm{SPH})$ were investigated in detail under different engine speeds and intake pressures $\left(\mathrm{P}_{\mathrm{i}}\right)$. The exhaust valve opening (EVO) timing was also swept with SPO to obtain maximum scavenging performance.

\section{Simulation setup}

\section{Baseline design of BUSDIG engine}

In this study, an uniflow engine with flat cylinder head and piston top was selected as the baseline design of a BUSDIG engine. Twelve evenly distributed scavenge intake ports were integrated to the cylinder block. The other engine specifications are shown in Table 1.

Table 1. Engine specifications.

\begin{tabular}{|l|l|}
\hline Bore & $80 \mathrm{~mm}$ \\
\hline Stroke & $100 \mathrm{~mm}$ \\
\hline Connecting rod & $180 \mathrm{~mm}$ \\
\hline Displacement & $0.5 \mathrm{~L}$ \\
\hline Compression ratio & $14: 1$ \\
\hline Cylinder head & Flat roof / 2 exhaust valves \\
\hline Piston & Flat piston \\
\hline
\end{tabular}

In order to achieve optimal scavenge performance of the 2-stroke BUSDIG engine, several design parameters of the scavenge ports, including scavenge port number (SPN), axis inclination angle (AIA), swirl orientation angle (SOA), scavenge port opening (SPO) timing and scavenge port height (SPH), were studied and optimized in this study. In addition, some other important operating conditions, e.g. intake pressure $\left(\mathrm{P}_{\mathrm{i}}\right)$, engine speed, exhaust valve opening (EVO) timing, also show significant impact on scavenge process. The effects of these operating parameters were also investigated in this study.

Fig. 1 schematically shows the definitions of AIA, SOA, SPO, SPH and their baseline values. As seen in the figure, a bigger AIA and smaller SOA would obtain a larger effective area. The location of the intake ports in $\mathrm{z}$ axis $\left(\mathrm{Z}_{\mathrm{SP}}\right)$ would directly control the scavenge port opening (SPO) timing. The width of each scavenge intake port was fixed at $20^{\circ}$ and the interval between ports was fixed at $10^{\circ}$, as indicated in Fig. 1.

In order to accommodate the scavenge ports for a multi-cylinder engine, the scavenge port number (SPN) was gradually reduced to 6 by directly removing the scavenge port pairs from two sides while retaining other scavenging ports, as shown in Fig. 2.

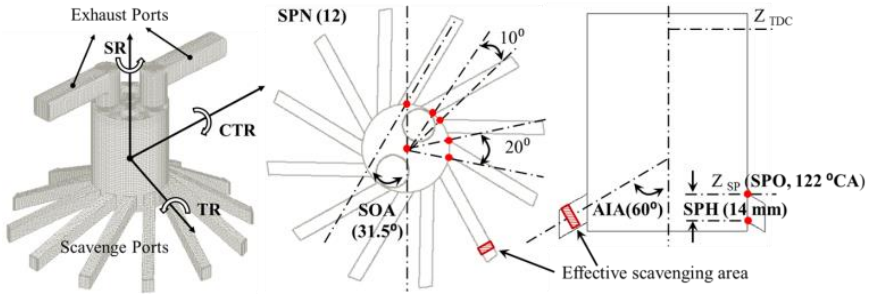

Figure 1. Definition of design parameters of scavenge ports and their baseline values.

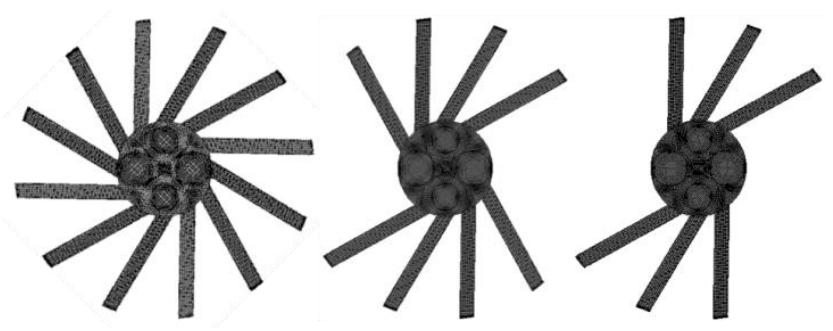

Figure 2. Layout of scavenge ports with SPN of 12,8 and 6.

\section{Numerical models}

In this study, the commercial CFD software STAR-CD was adopted to perform the simulations. Reynolds-Averaged Navier Stokes (RANS) approach was applied with Re-Normalisation Group (RNG) $\mathrm{k}-\varepsilon$ turbulence model in the simulations. Pressure-Implicit with Splitting of Operators (PISO) algorithm was used to solve the equations. The heat transfer was implemented through the general form of the enthalpy conservation equation for the fluid mixture. The Angelberger wall function was used for the simulation of the wall heat transfer. The detailed description of these models can be found in Ref. [22].

\section{Simulation conditions}

The scavenging process of the designed 2-stroke BUSDIG engine was evaluated with both cold and fired in-cylinder conditions. The corresponding simulation conditions, including exhaust valve parameters, initial and boundary conditions, are shown in Table 2. The pressure boundary type was applied to the inlets of scavenge ports and the outlets of exhaust ports. The arbitrary sliding interface (ASI) was applied between the scavenge ports and the cylinder liner to control the attachment and detachment with the piston movement. ASI was also applied to control the connectivity between exhaust domains and cylinder domain with the movement of exhaust valves. One dimensional (1D) simulations were performed to obtain more realistic fired in-cylinder conditions using WAVE [23]. In the cases with fired conditions, the initial mixture components in the cylinder are pure burned gas, i.e. $\mathrm{CO}_{2}, \mathrm{H}_{2} \mathrm{O}$ and $\mathrm{N}_{2}$. In the cases with cold conditions, the initial mixture components are pure air, i.e. $\mathrm{O}_{2}$ and $\mathrm{N}_{2}$. The same cold/fired simulation conditions, as shown in Table 2, were applied to all the cold/fired CFD simulations in this study. The multicycle simulations were carried out for the cold flow simulations. The fired CFD simulations were carried out from $100{ }^{\circ} \mathrm{CA}$ after top dead 
center (ATDC) to $280{ }^{\circ} \mathrm{CA}$ (i.e. $80{ }^{\circ} \mathrm{CA}$ before TDC), including the whole scavenging process.

Table 2. Simulation conditions.

\begin{tabular}{|l|l|l|}
\hline Parameters & Cold condition & Fired condition \\
\hline Exhaust valve duration $(\mathrm{ED})$ & $126^{\circ} \mathrm{CA}$ ATDC & $126^{\circ} \mathrm{CA}$ ATDC \\
\hline Exhaust valve lift $(\mathrm{EL})$ & $8.64 \mathrm{~mm}$ & $8.64 \mathrm{~mm}$ \\
\hline Exhaust valve opening (EVO) & $127^{\circ} \mathrm{CA}$ ATDC & $127^{\circ} \mathrm{CA}$ ATDC \\
\hline Initial conditions @ $100{ }^{\circ} \mathbf{C A}$ ATDC & $1665 \mathrm{~K}$ \\
\hline Cylinder temperature $\left(\mathrm{T}_{\text {cylinder }}\right)$ & $400 \mathrm{~K}$ & $8.6 \mathrm{bar}$ \\
\hline Cylinder pressure $\left(\mathrm{P}_{\text {cylinder }}\right)$ & $2 \mathrm{bar}$ & $350 \mathrm{~K}$ \\
\hline Intake temperature $\left(\mathrm{T}_{\text {intake }}\right)$ & $300 \mathrm{~K}$ & $800 \mathrm{~K}$ \\
\hline Exhaust temperature $\left(\mathrm{T}_{\text {exhaust }}\right)$ & $350 \mathrm{~K}$ & $1.06 \mathrm{bar}$ \\
\hline Exhaust pressure $\left(\mathrm{P}_{\text {exhaust }}\right)$ & $1.01 \mathrm{bar}$ & \multicolumn{2}{|l}{} \\
\hline Boundary conditions & \multicolumn{3}{l}{} \\
\hline Intake temperature $\left(\mathrm{T}_{\text {intake }}\right)$ & $300 \mathrm{~K}$ & $350 \mathrm{~K}$ \\
\hline Exhaust temperature $\left(\mathrm{T}_{\text {exhaust }}\right)$ & $350 \mathrm{~K}$ & $800 \mathrm{~K}$ \\
\hline Exhaust pressure $\left(\mathrm{P}_{\text {exhaust }}\right)$ & $1.01 \mathrm{bar}$ & $1.06 \mathrm{bar}$ \\
\hline Piston head temperature $\left(\mathrm{T}_{\text {head }}\right)$ & $340 \mathrm{~K}$ & $440 \mathrm{~K}$ \\
\hline Piston top temperature $\left(\mathrm{T}_{\text {piston }}\right)$ & $360 \mathrm{~K}$ & $522 \mathrm{~K}$ \\
\hline Cylinder liner temperature $\left(\mathrm{T}_{\text {liner }}\right)$ & $320 \mathrm{~K}$ & $384 \mathrm{~K}$ \\
\hline
\end{tabular}

\section{Mesh sensitivity study}

The moving meshes were generated in ES-ICE software using the mapping method. Three different meshes with average grid size of 2 $\mathrm{mm}, 1.6 \mathrm{~mm}$ and $1 \mathrm{~mm}$ were generated to examine the sensitivity of simulation results to the mesh quality. Correspondingly, the total grid number is $180,690,326,092$ and 921,810 , respectively. The engine mesh with average grid size of $1.6 \mathrm{~mm}$ at bottom dead center (BDC) has been shown in Fig. 1.

The cold in-cylinder conditions were used to perform the mesh sensitivity study. The engine speed and intake pressure were fixed at $2000 \mathrm{rpm}$ and 2 bar, respectively. Fig. 3 compares the in-cylinder average pressure and temperature profiles from different engine meshes. As shown in Fig. 3, the in-cylinder pressure and temperature shows little sensitivity to the adopted three mesh sizes. The profiles overlap each other and only show slight differences at TDC.

The swirl ratio (SR), tumble ratio (TR) and cross tumble ratio (CTR), as defined in Fig. 1, are used to characterize the in-cylinder flow motion and calculated as following [24]:

$S R(\theta)=\frac{\sum_{i}^{m} v_{i}(\theta) r_{i}(\theta) V_{i}(\theta) \rho_{i}(\theta)}{\frac{2 \pi n}{60} \sum_{i}^{m} r_{i}(\theta)^{2} V_{i}(\theta) \rho_{i}(\theta)}$

where $n$ is engine speed, $\theta$ the crank angle, $i$ the cell number, $V_{i}(\theta)$ the cell volume, $\rho_{i}(\theta)$ the cell density, $v_{i}(\theta)$ and $r_{i}(\theta)$ are the tangential velocity and radius respectively in the cylindrical coordinate with $z$ axis as the swirl axis. With the same method, the swirl axis along with the cylindrical coordinate system in Equation (1) is then replaced as the tumble/cross tumble axis to evaluate TR/CTR. The tumble and cross tumble axis are parallel to $y$ - and $x$-axis respectively and cross the central line of the cylinder and the central point between maximum and minimum $\mathrm{z}$ value of the cylinder.

The in-cylinder flow motion calculated with different meshes also shows little differences, as indicated by the overlapped profiles of swirl and tumble ratios in Fig. 4. It can be also inferred that the incylinder flow enabled by the current scavenge ports design is dominated by the swirl flow motion. In this study, a swirl ratio no less than 3 is expected to enhance the mixing between the fuel droplets and in-cylinder charge and meanwhile prevent the wall wetting. The cross tumble ratio (CTR) is also very small, and for simplicity it is not shown here.

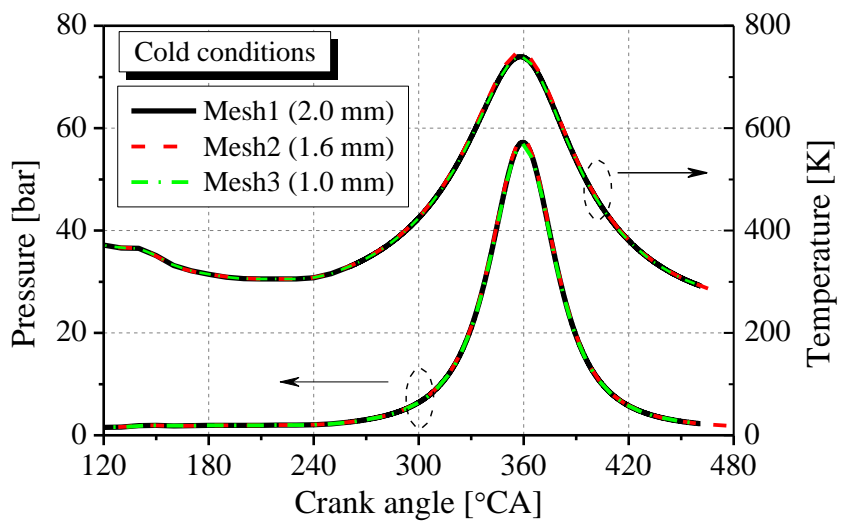

Figure 3. Effect of grid size on in-cylinder average pressure and temperature (2000 rpm, $\mathrm{P}_{\mathrm{i}}=2$ bar, cold condition).

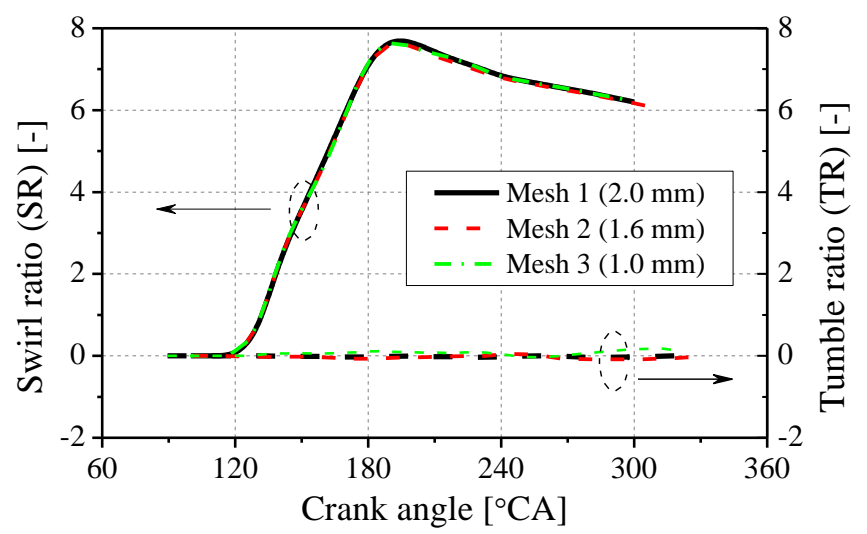

Figure 4. Effect of grid size on $\mathrm{SR}$ and TR (2000 rpm, $\mathrm{P}_{\mathrm{i}}=2$ bar, cold condition).

Four scavenge parameters, i.e. delivery ratio (DR), trapping efficiency (TE), scavenging efficiency (SE) and charging efficiency (CE), are used to characterise the scavenging performance of the BUSDIG engine. They are defined as following [23]:

$$
\begin{aligned}
& D R=\frac{\text { delivered fresh charge mass }}{\text { reference mass }} \\
& T E=\frac{\text { mass of delivered fresh charge retained in the cylinder }}{\text { total mass of delivered fresh charge }}=\frac{C E}{D R}
\end{aligned}
$$

Page 3 of 13 
$S E=\frac{\text { mass of delivered fresh charge retained in the cylinder }}{\text { total mass of trapped cylinder charge }}$

$C E=\frac{\text { mass of delivered fresh charge retained in the cylinder }}{\text { reference mass }}$

The reference mass in above equations is calculated by the displaced volume multiplied by the ambient air density.

As can be seen in Fig. 5, the grid size actually shows only slight impact on scavenge parameters. The biggest grid size $(2 \mathrm{~mm})$ leads to slightly higher DR compared to the smallest grid size $(1 \mathrm{~mm})$. The intermediate grid size $(1.6 \mathrm{~mm})$ shows nearly consistent values with the smallest grid size. Therefore, the intermediate grid size of $1.6 \mathrm{~mm}$ was adopted for the numerical simulations in the following studies.

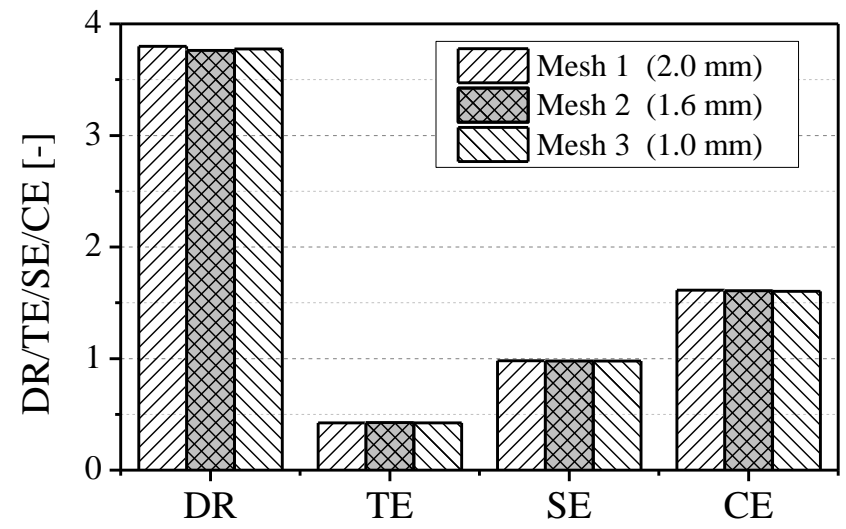

Figure 5. Effect of grid size on DR, TE, SE and CE (2000 rpm, $\mathrm{P}_{\mathrm{i}}=2$ bar, cold condition)

\section{Cycle convergence of simulations}

The multi-cycle simulations were performed with the cold in-cylinder conditions to examine the impact of initial conditions on the simulation results. The engine speed and intake pressure were fixed at $2000 \mathrm{rpm}$ and 2 bar, respectively.

Fig. 6 and Fig. 7 compare the swirl ratios and scavenging parameters respectively among different cycles. As can be seen in the figures, both in-cylinder flow motion and scavenging parameters can obtain good convergence at the second cycle. The swirl ratio and DR in the first cycle are relatively higher than the converged results, while TE is a little lower. SE and CE are similar between different cycles. Therefore, the simulation results from the second cycle are considered appropriate to represent the scavenging performance of a specific design. Regarding the simulations with fired conditions, the multi-cycle simulation is not possible via CFD without a validated combustion model. As the combustion process is not included in this study, the results from the first cycle are analyzed for those simulations with fired conditions.

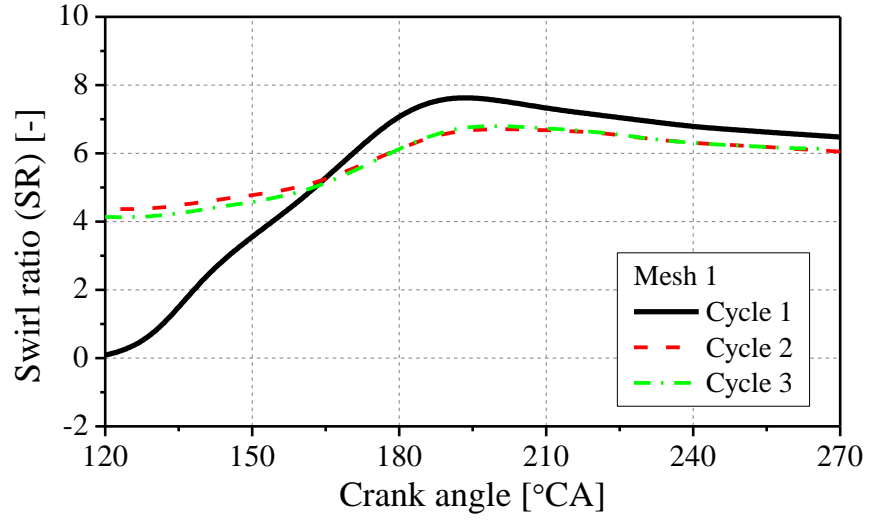

Figure 6. Evolution of swirl ratio (SR) among different cycles (2000 rpm, $\mathrm{P}_{\mathrm{i}}=2$ bar, cold condition) .

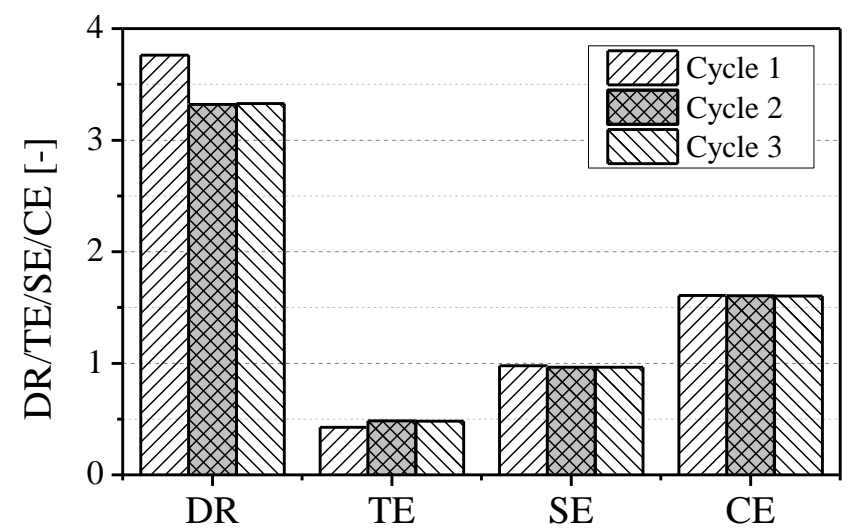

Figure 7. DR, TE, SE and CE among different cycles $\left(2000 \mathrm{rpm}, \mathrm{P}_{\mathrm{i}}=2\right.$ bar, cold condition)

\section{Results and discussion}

\section{Effect of scavenge port number (SPN)}

Firstly, the effect of scavenge port number (SPN) is investigated with cold in-cylinder condition under different engine speeds and intake pressures.

Fig. 8 compares DR, TE, SE and CE under different engine speeds. The intake pressure $P_{i}$ is fixed at 2 bar. At low engine speed (i.e. $1000 \mathrm{rpm}$ ), the increase in the absolute scavenging duration leads to significantly higher DR and complete scavenge ( $\mathrm{SE}=100 \%)$. The TE at lower engine speed is the lowest because of the significantly increased DR. As the engine speed increases, the DR and SE gradually reduce and TE increases. $\mathrm{CE}$ is comparable under different engine speeds but it does show slightly higher value at engine speed of $2000 \mathrm{rpm}$. Therefore, too long or too short scavenging duration is not preferable to achieve high CE. At the low engine speed, the increased scavenge duration would also cause the flow of in-cylinder fresh air into the exhaust and scavenge ports when the in-cylinder pressure exceeds the exhaust/intake pressure during the compression stroke. At the high engine speed, the reduced scavenging duration limits the delivery ratio, as well as the CE.

Regarding the effect of scavenge port number (SPN), it can be seen in Fig. 8 that the scavenging performances are improved with more 
scavenge ports. Specifically, a larger SPN increases DR and CR but shows no impact on TE and SE under low engine speeds. The impact of SPN on the scavenging performance is more pronounced at higher engine speeds as shown by the results of $\mathrm{SPN}=12$ and $\mathrm{SPN}=6$.

However, it is noted in Fig. 9 that the decrease of SPN enhances the in-cylinder flow motion. The swirl ratio, which dominates the incylinder flow, gradually increases as the SPN is reduced. The tumble flow is very weak in all cases and TR and CTR show little difference between different SPN cases.

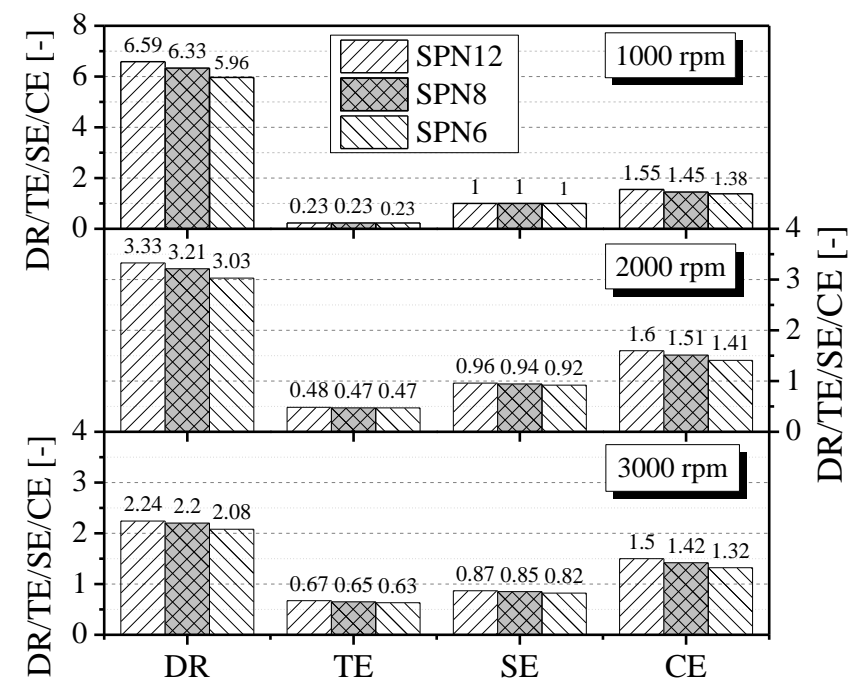

Figure 8. Effect of SPN on DR, TE, SE and CE under different engine speeds $\left(\mathrm{P}_{\mathrm{i}}=2\right.$ bar, cold condition $)$

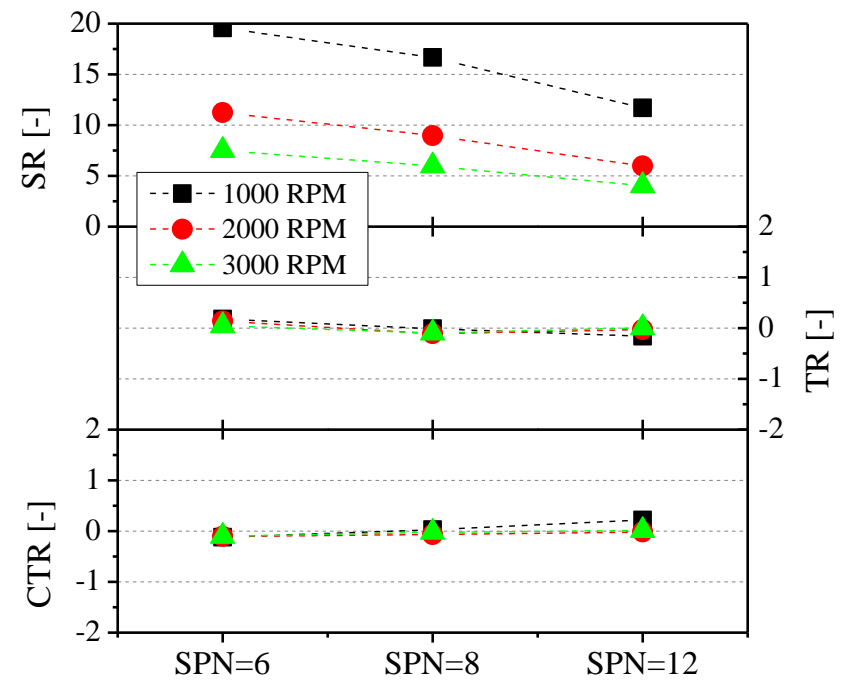

Figure 9. Effect of SPN on SR, TR and CTR at $280{ }^{\circ} \mathrm{CA}$ under different engine speeds $\left(\mathrm{P}_{\mathrm{i}}=2\right.$ bar, cold condition $)$.

Fig. 10 compares DR, TE, SE and CE under different intake pressures $\left(\mathrm{P}_{\mathrm{i}}\right)$. As shown in the figure, DR increases more significantly than CE with Pi increasing from 1.2 to 2 bar, leading to higher SE but lower TE with $\mathrm{P}_{\mathrm{i}}$. As expected, the reduced SPN has negative impact on all four scavenge parameters for all $\mathrm{P}_{\mathrm{i}}$. Regarding the in-cylinder flow motion, the higher intake pressure leads to stronger swirl motion and SR gradually decreases with SPN.

In order to examine the effect of SPN on the scavenging performance under different operating engine speeds and intake pressures, the percentage change $(\Delta)$ of four scavenge parameters is calculated using the results of $\mathrm{SPN}=12$ and 6 . For example, the percentage change of DR under a given operating condition is calculated as following:

$\Delta D R=\left(1-\frac{\mathrm{DR}_{\mathrm{SPN}=6}}{\mathrm{DR}_{\mathrm{SPN}=12}}\right) \times 100 \%$

The maximum percentage changes of DR, TE, SE and CE under different operating conditions are $9.6 \%, 5.8 \%, 8.0 \%$ and $12 \%$. Therefore, the reduction of SPN shows more impact on CE and has the least effect on TE.

The reduction of SPN would dramatically enhance the swirl motion but have little impact on the tumble motion. But it should be noted the swirl ratio is high enough to enhance the fuel/air mixing even under high engine speed and low intake pressure, as shown in Fig. 9 and 11 .

Considering both the overall effect of SPN on scavenging performance discussed above and the future application to multicylinder engine, 8 unevenly distributed scavenge ports are used to investigate the effect of remaining key design parameters on scavenging performance.

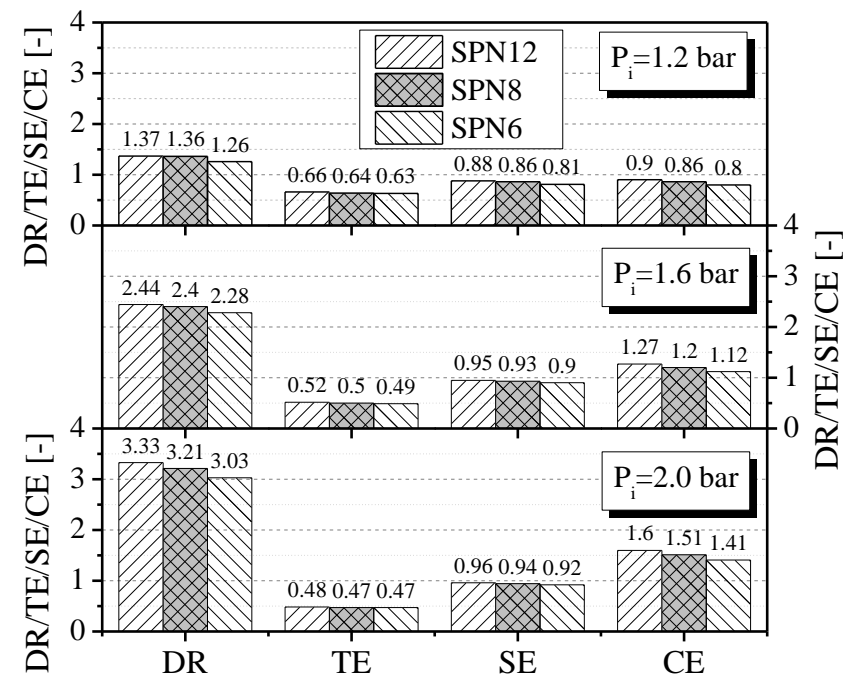

Figure 10. Effect of SPN on DR, TE, SE and CE under different intake pressures (2000 rpm, cold condition)

Page 5 of 13 


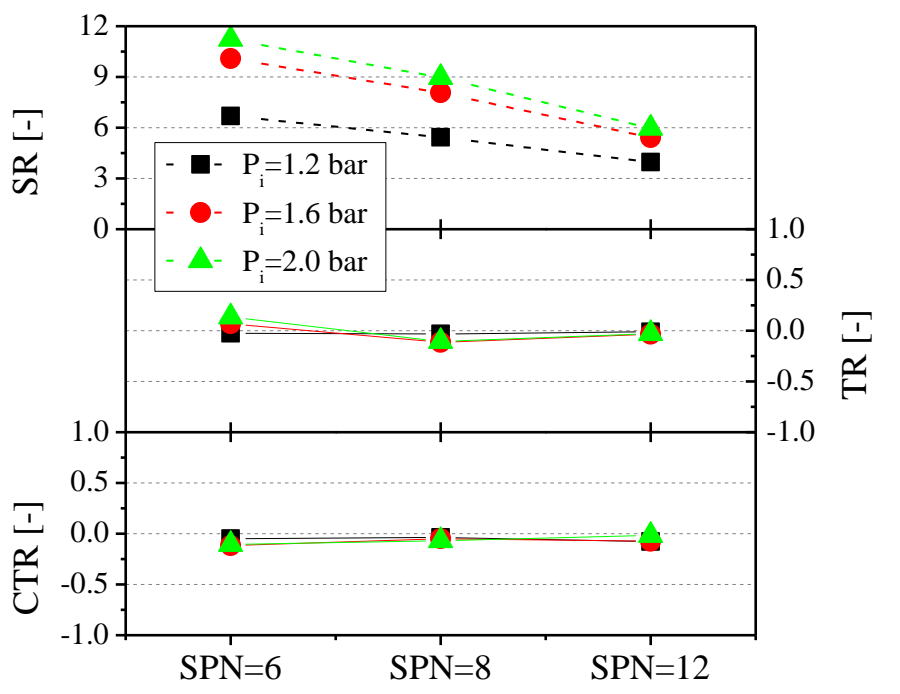

Figure 11. Effect of SPN on SR, TR and CTR at $280{ }^{\circ} \mathrm{CA}$ under different intake pressures (2000 rpm, cold condition).

\section{Effect of AIA and SOA}

Effects of the Axis Inclination Angle (AIA) and Swirl Orientation Angle (SOA) are presented in this section. In addition to the cold flow simulations, the simulations with fired in-cylinder condition were also performed to explore the effect of AIA and SOA on the scavenging process with a more realistic in-cylinder condition. The engine speed and intake pressure are fixed at $2000 \mathrm{rpm}$ and $2 \mathrm{bar}$, respectively.

Fig. 12 shows the impact of AIA on scavenge parameters with SOA of $31.5^{\circ}$ and cold in-cylinder condition. As shown in the figure, AIA shows weak impact on scavenge parameters. CE and SE are improved slightly with a bigger AIA because of the increased effective flow area. The swirl flow motion is also increased with AIA and peaks at $75^{\circ}$ because of the increased tangential velocity component, as shown in Fig. 13. Any further increase in AIA to $90^{\circ}$ would deteriorate the swirl flow because of the enhanced interaction of the intake flow jects with the rising piston.

Compared to the cold flow results, the scavenging process is more restricted under the fired condition because of increased in-cylinder pressure and temperature. As shown in Fig. 14, the DR and CE for each AIA are significantly lower than the cold flow values. Although the changing trend in DR and CE with AIA is similar under both cold and fired conditions, their differences are more obvious under the fired condition. DR gradually increases from 1.66 at $\mathrm{AIA}=45^{\circ}$ to 1.96 at $\mathrm{AIA}=90^{\circ}$, and $\mathrm{CE}$ increases from 1.03 to 1.19. However, AIA shows only slight impact on SE which increases from 0.92 at $\mathrm{AIA}=45^{\circ}$ to 0.95 at $\mathrm{AIA}=90^{\circ}$. TE slightly decreases from 0.62 to 0.61 .

Regarding the in-cylinder flow motion with hot burned gases, a moderate AIA can produce a higher SR as shown in Fig 15, similar to the cold flow results. The tumble flow motion is very weak and AIA shows no impact on TR and CTR under both cold and fired conditions.

Page 6 of 13

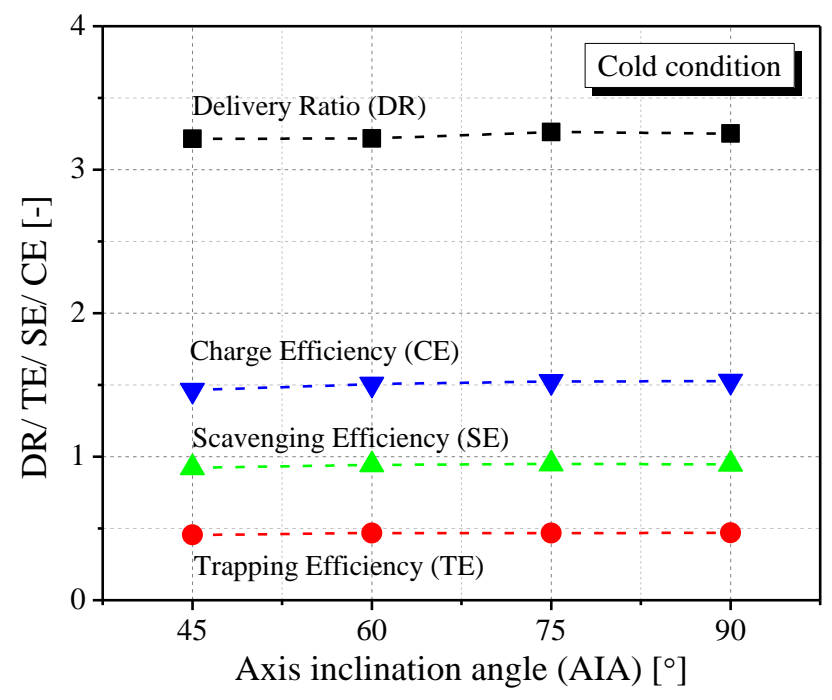

Figure 12. Effect of AIA on DR, TE, SE and CE $\left(\mathrm{SOA}=31.5^{\circ}, 2000 \mathrm{rpm}, \mathrm{P}_{\mathrm{i}}=2\right.$ bar, cold condition).

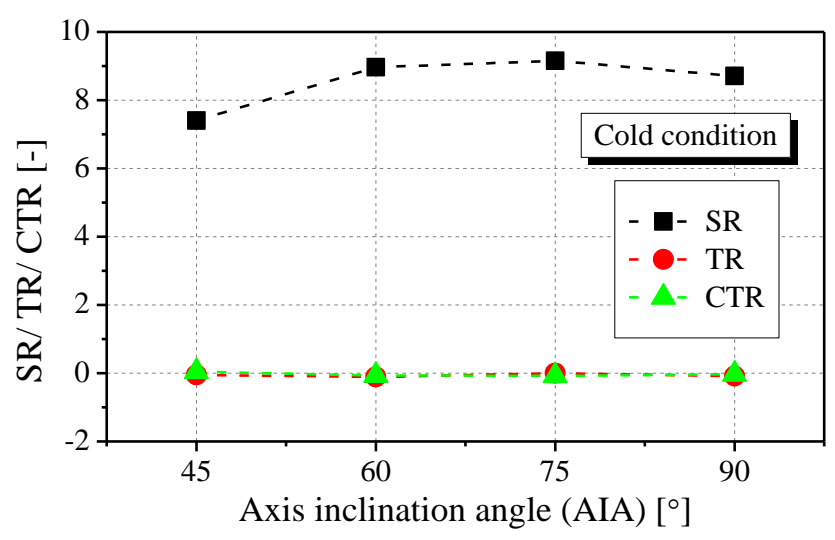

Figure 13. Effect of AIA on SR, TR and CTR at $280^{\circ} \mathrm{CA}\left(\mathrm{SOA}=31.5^{\circ}, 2000\right.$ rpm, $\mathrm{P}_{\mathrm{i}}=2$ bar, cold condition).

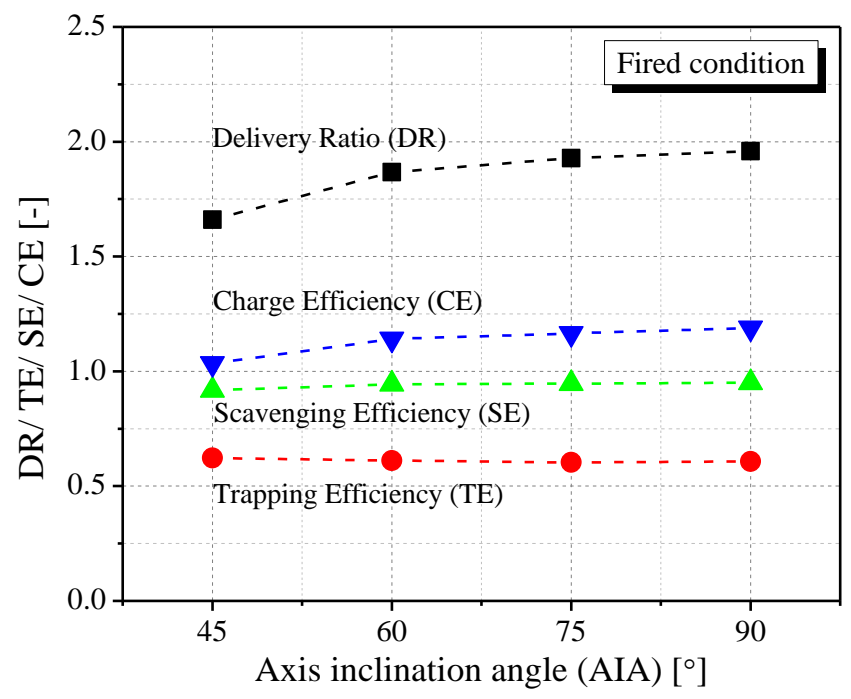

Figure 14. Effect of AIA on DR, TE, SE and CE (SOA=31.5 $, 2000 \mathrm{rpm}, \mathrm{P}_{\mathrm{i}}=2$ bar, fired condition). 


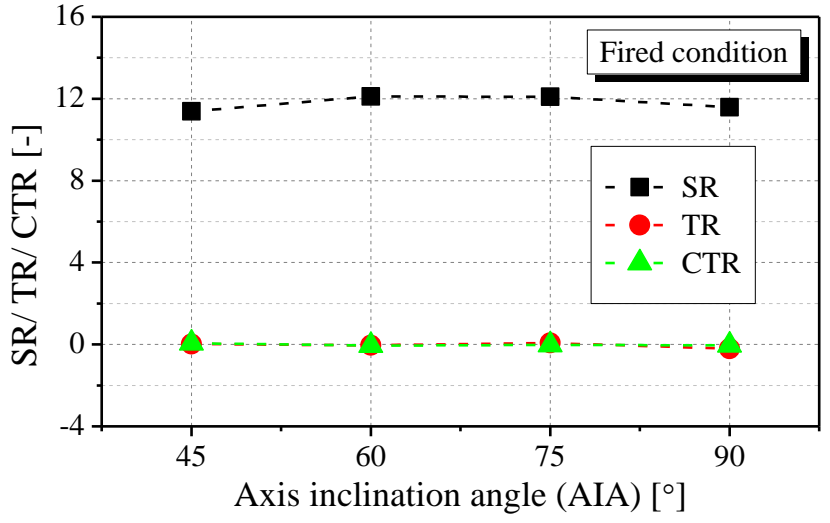

Figure 15. Effect of AIA on SR, TR and CTR at $280{ }^{\circ} \mathrm{CA}\left(\mathrm{SOA}=31.5^{\circ}, 2000\right.$ rpm, $\mathrm{P}_{\mathrm{i}}=2$ bar, fired condition).

Fig. 16 shows the effect of SOA on scavenge parameters with AIA of $60^{\circ}$ under cold in-cylinder condition. DR gradually decreases with SOA because the significantly increased swirl motion as shown in Fig 17 would inhibit the gas flowing from scavenge ports to exhaust ports. CE increases slightly with SOA decreasing from $45^{\circ}$ to $20^{\circ}$. However, the further decrease of SOA leads to lower CE, indicating increased short-circuiting of the fresh gas. Figure 18 shows that both $\mathrm{SE}$ and CE are slightly affected by SOA and peak at $\mathrm{SOA}=20^{\circ}$ under fired condition.

Fig. 19 compares the residual gas fraction (RGF) profiles in the cylinder and exhaust ports. The scavenge process begins from top right where RGF in the cylinder and exhaust ports is 1 . Then RGF in the cylinder gradually decreases with the scavenging process. The decrease of RGF in the exhaust ports indicates the occurrence of short-circuiting. Compared to $\mathrm{SOA}=20^{\circ}$, the short-circuiting takes place at the very beginning of scavenging process and gradually increases when $\mathrm{SOA}=0^{\circ}$ is adopted. The RGF distribution at 170 ${ }^{0} \mathrm{CA}$ indicates fresh charge coming from scavenge ports with SOA of $0^{0}$ would concentrate in the cylinder center and directly flow out of the exhaust valves along with the cylinder axis, leading to earlier and stronger short-circuiting.

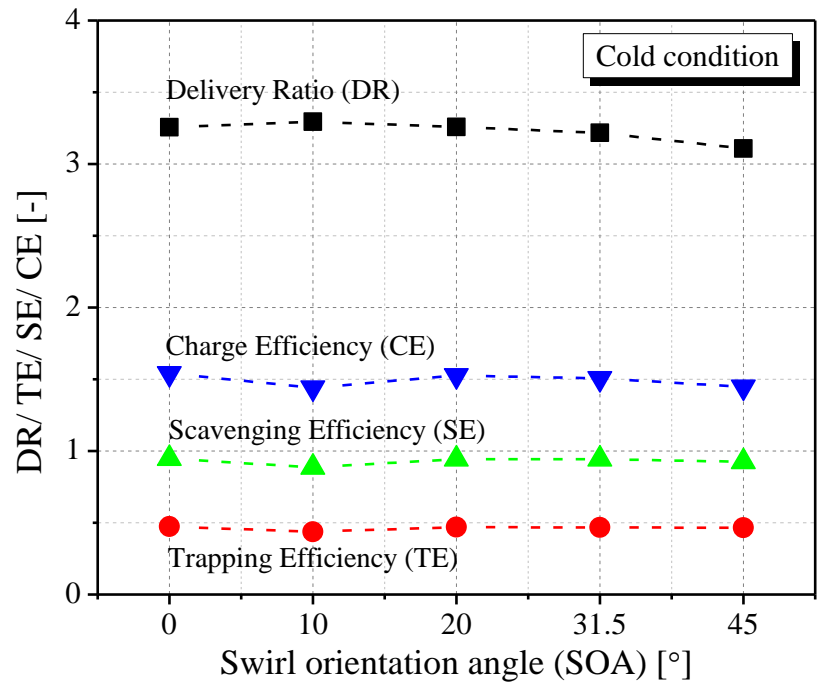

Figure 16. Effect of SOA on DR, TE, SE and CE (AIA $=60^{\circ}, 2000 \mathrm{rpm}, \mathrm{P}_{\mathrm{i}}=2$ bar, cold condition)

Page 7 of 13

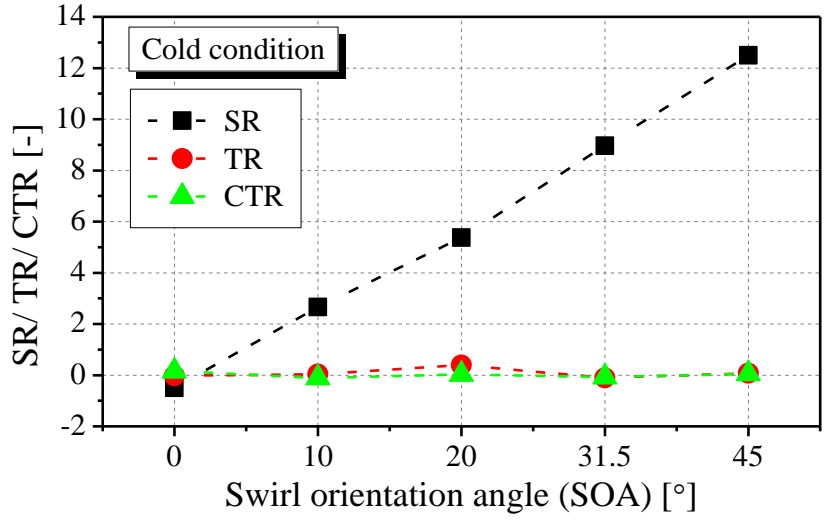

Figure 17. Effect of SOA on SR, TR and CTR at $280{ }^{\circ} \mathrm{CA}\left(\mathrm{AIA}=60^{\circ}, 2000\right.$ rpm, $\mathrm{P}_{\mathrm{i}}=2$ bar, cold condition).

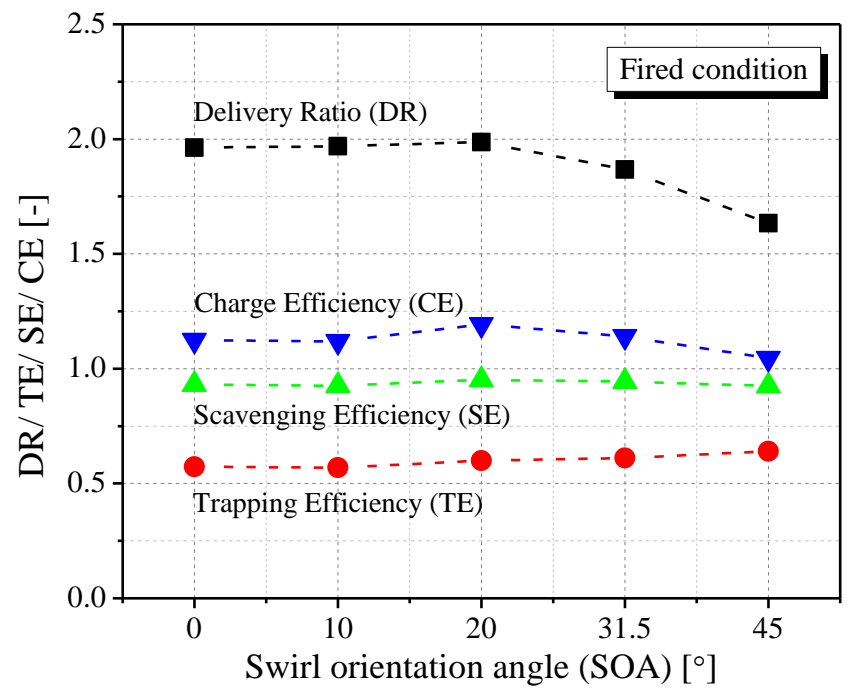

Figure 18. Effect of SOA on DR, TE, SE and CE (AIA $=60^{\circ}, 2000 \mathrm{rpm}, \mathrm{P}_{\mathrm{i}}=2$ bar, fired condition).

The SR shows strong correlations with SOA under both cold and fired conditions, as shown in Fig. 17 and 20. SOA shows little impact on the tumble flow motion.

In general, the effects of AIA and SOA on the scavenging process are similar for cold and fired conditions. But the impact is more pronounced under the fired condition. The DR and CE become lower but the TE is increased in the presence of hot burned gases. SE is similar under both conditions.

As indicated by the above results, a larger AIA shows higher DR, SE and $\mathrm{CE}$, while a moderate SOA can produce higher values of DR, SE and CE. Meanwhile, the swirl motion is stronger enough to enhance the in-cylinder mixing of air and directly injected fuel in all cases. In order to maximize the scavenging performance, the combination of $\mathrm{AIA}=90^{\circ}$ and $\mathrm{SOA}=20^{\circ}$ was then evaluated under different operating conditions and compared to the baseline design (AIA $=60^{\circ}$, $\mathrm{SOA}=31.5^{\circ}$ ). The results are included in Appendix. Compared to the baseline design, the scavenge port design with $\mathrm{AIA}=90^{\circ}$ and $\mathrm{SOA}=20^{\circ}$ shows higher $\mathrm{CE}$. SE is also improved at higher engine speeds. The dominant swirl flow motion generated with this new design is still rather high under different engine speeds and intake 
pressures. Therefore, the optimal design with $\mathrm{AIA}=90^{\circ}$ and $\mathrm{SOA}=20^{\circ}$ was used in the following study.

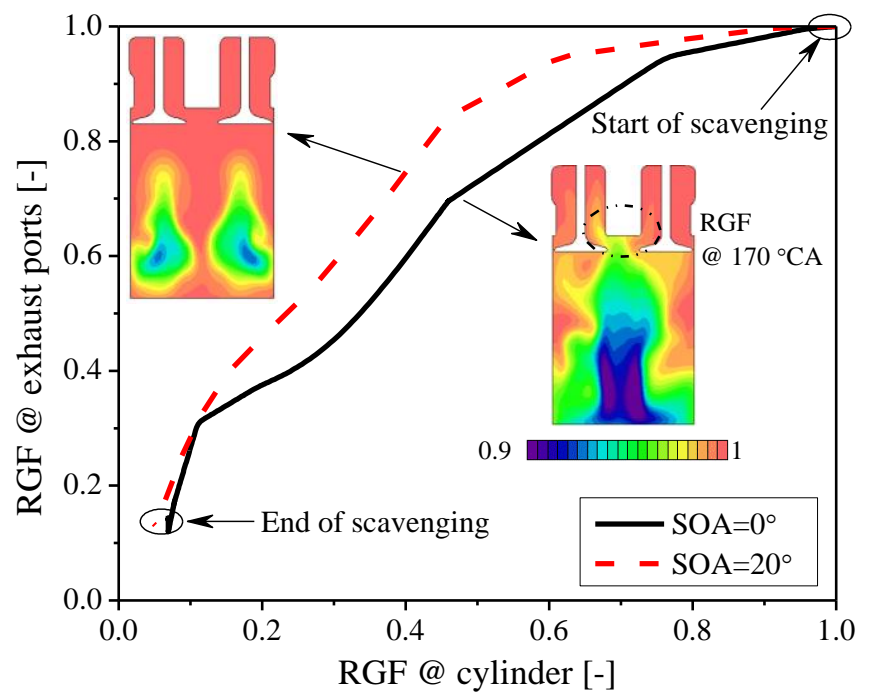

Figure 19. Comparison of RGF profiles in the cylinder and exhaust ports, and the RGF distributions at $170{ }^{\circ} \mathrm{CA}\left(\mathrm{AIA}=60^{\circ}, 2000 \mathrm{rpm}, \mathrm{P}_{\mathrm{i}}=2\right.$ bar, fired condition)

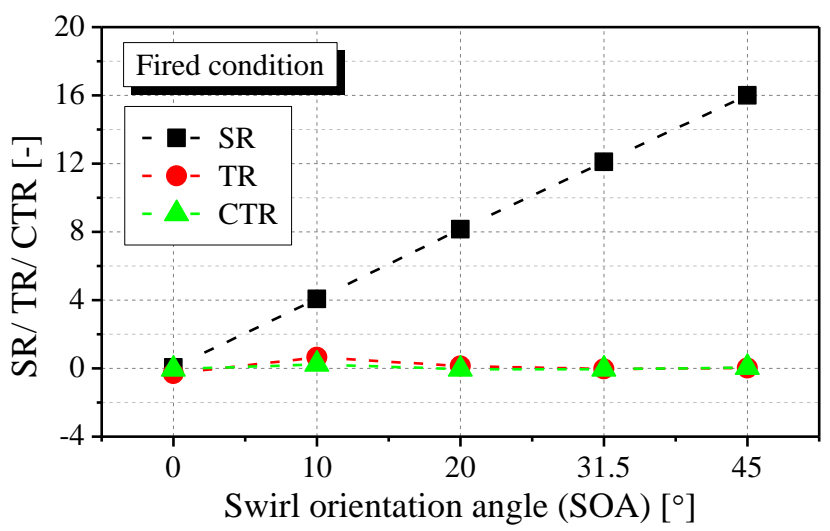

Figure 20. Effect of SOA on SR, TR and CTR at $280{ }^{\circ} \mathrm{CA}\left(\mathrm{AIA}=60^{\circ}, 2000\right.$ $\mathrm{rpm}, \mathrm{P}_{\mathrm{i}}=2$ bar, fired condition).

\section{Effect of scavenge port opening (SPO) timing}

The location of scavenge intake ports would directly control the scavenge port opening (SPO) timing. The EVO is also adjusted to evaluate the optimal matching between intake and exhaust process to achieve the best scavenging performance. Three SPOs and EVOs were tested in this study. The schematic diagram of the normalized scavenging area and exhaust valve profiles are shown in Fig 21. The exhaust duration (ED) is fixed as $126{ }^{\circ} \mathrm{CA}$. The engine speed and intake pressure are fixed at $2000 \mathrm{rpm}$ and 2 bar, respectively. For brevity, only the simulation results with fired condition are presented.

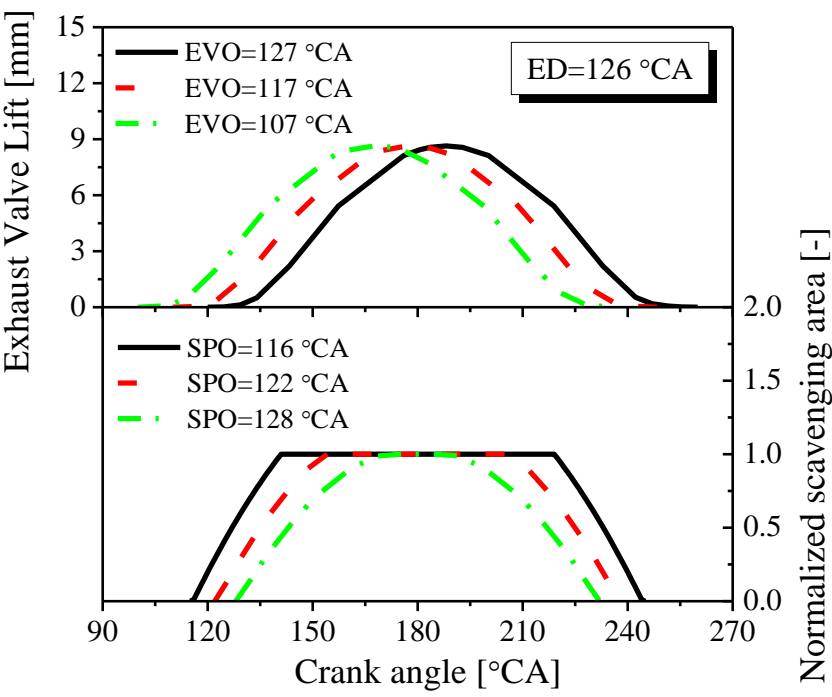

Figure 21. Schematic diagram of the normalized scavenging area and exhaust valve profiles.

The SPO and EVO have significant impact on DR, TE, SE and CE, as shown in Fig. 22. The earlier EVO leads to higher DR, SE and CE, which is less significant with early SPO $\left(116{ }^{\circ} \mathrm{CA}\right)$ but more significant with late SPO $\left(128{ }^{\circ} \mathrm{CA}\right)$. Therefore, a later SPO with an earlier EVO produce higher DR, SE and CE. The reason can be attributed to the increased blow-down duration which is defined as the duration between EVO and SPO. The longer blow-down duration leads to more residual gas blowing out of the cylinder, which avoids over-mixing between fresh air and residual gas and facilitates the scavenging process. However, the scavenging performance with a later SPO is deteriorated dramatically as the EVO is delayed, leading to lower DR, SE and CE. On the contrary, an early SPO (i.e. $116{ }^{\circ} \mathrm{CA}$ ) can lead to slightly higher DR, SE and CE than a later SPO when a late EVO is adopted. The reason can be attributed to the increased scavenging duration which is defined as the duration when both scavenge ports and exhaust valves are opened simultaneously. Therefore, the scavenging performance is less affected by the changing of EVO when an early SPO is adopted, but shows much higher sensitivity to EVO when a later SPO is adopted, as seen in Fig. 22.

As shown in Fig. 23, an earlier EVO leads to a higher SR with a fixed SPO timing because of a more complete blow-down process. When the SPO is delayed to as late as $128{ }^{\circ} \mathrm{CA}$, the shortened scavenging duration leads to only slight differences of SR among EVOs. For a fixed EVO, the delaying of SPO timing leads to lower SR because of the shortened scavenging duration. However, it is found the SR is slightly lower for $\mathrm{SPO}=116{ }^{\circ} \mathrm{CA}$ compared to $122{ }^{\circ} \mathrm{CA}$ when the EVO is fixed at $107{ }^{\circ} \mathrm{CA}$. The reason can be attributed to more dramatically deteriorated flow motion after BDC with $\mathrm{SPO}=116{ }^{\circ} \mathrm{CA}$ because some fresh charge would be pushed back into scavenge ports again by the piston. This also explains the gradually reduced $\mathrm{CE}$ from SPO of 128 to $116{ }^{\circ} \mathrm{CA}$ when EVO of $107{ }^{\circ} \mathrm{CA}$ is adopted, as shown in Fig. 22. However, it should be noted the swirl motions with different combinations of SPO and EVO are still strong enough to enhance the mixing between fresh air and direct injected fuel although SPO and EVO show obvious impact on SR. 


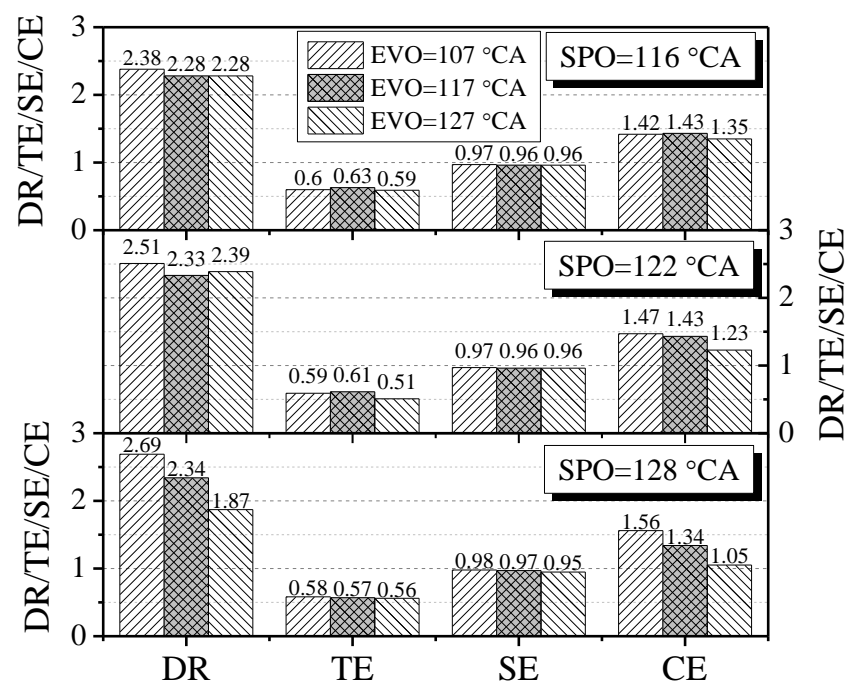

Figure 22. Effect of SPO and EVO on DR, TE, SE and CE (SPH=14 mm, $2000 \mathrm{rpm}, \mathrm{P}_{\mathrm{i}}=2$ bar, fired condition).

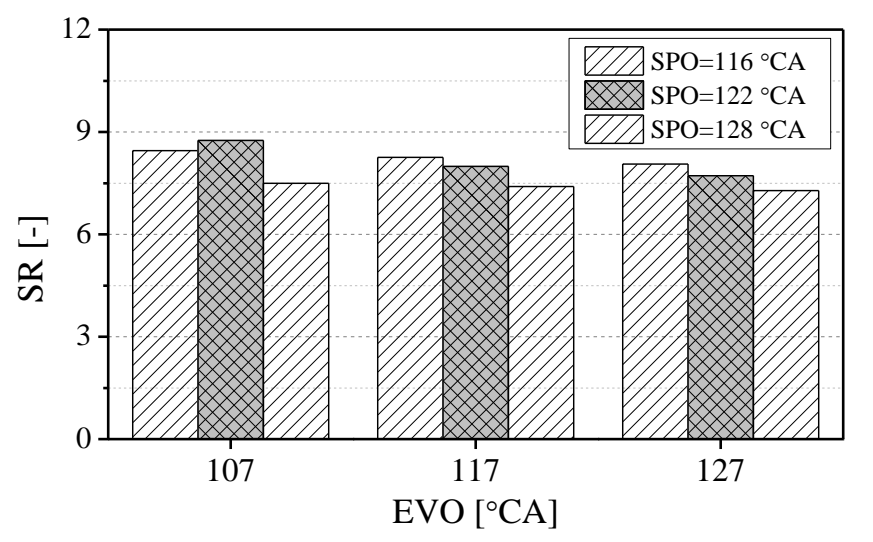

Figure 23. Effect of SPO and EVO on SR at $280{ }^{\circ} \mathrm{CA}(\mathrm{SPH}=14 \mathrm{~mm}, 2000$ rpm, $\mathrm{P}_{\mathrm{i}}=2$ bar, fired condition).

Another key issue relating to the SPO and EVO is the effective compression ratios (ECR) and effective expansion ratios (EER). The compression ratio would directly control the in-cylinder thermal conditions at TDC and the combustion performance, especially for the advanced combustion concept, e.g. controlled auto-ignition combustion (CAI). The expansion ratio directly affects the power stroke and thermal efficiency. A larger expansion ratio is expected to achieve a longer power stroke and higher thermal efficiency. In this study, the effective compression ratio and expansion ratio were calculated respectively to consider the intake and exhaust valve events. Fig. 24 compares the values of ECR and EER with different SPOs and EVOs. When the EVO is fixed at $117{ }^{\circ} \mathrm{CA}$, the exhaust valve profile is asymmetric to BDC, leading to same ECR and EER around 11. Apart from this, the ECR and EER are determined by $\mathrm{EVC} / \mathrm{SPC}$ and EVO/SPO and show a trade-off between each other. The lower limit of ECR and EER is around 10.22, which is determined by the EVC and EVO respectively. However, compared to the SPO of $116^{\circ} \mathrm{CA}$, a later SPO of $128{ }^{\circ} \mathrm{CA}$ can extend the higher limit of ECR or EEC to 11.98.

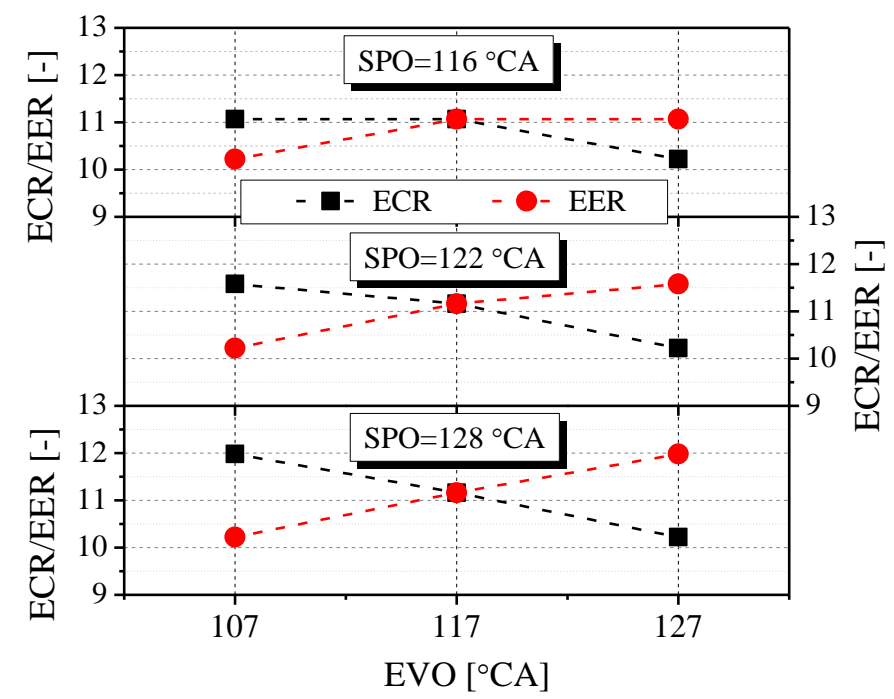

Figure 24. Effective compression ratios (ECR) and expansion ratios (EER) with different SPOs and EVOs.

\section{Effect of scavenge port height (SPH)}

In this section, the scavenge port height (SPH) was increased from original $14 \mathrm{~mm}$ to $18 \mathrm{~mm}$ to evaluate the effect of SPH on the scavenging performance. The SPO and EVO were also adjusted to evaluate its optimal matching to achieve the best scavenging performance. Fig. 25 shows the effect of SPO and EVO on DR, TE, SE and CE with SPH of $18 \mathrm{~mm}$. It should be noted that a later SPO of $128{ }^{\circ} \mathrm{CA}$ was not investigated because the lower part of scavenge ports with SPH of $18 \mathrm{~mm}$ will extend beyond the BDC location and cannot be fully opened. Compared to the SPH of $14 \mathrm{~mm}$ (Fig. 22), higher scavenge ports show only slight improvement on DR and CE when earlier EVOs (i.e. 107 and $117{ }^{\circ} \mathrm{CA}$ ) are adopted. When the EVO is delayed to $127^{\circ} \mathrm{CA}$, the increase in SPH even leads to slight decrease of $\mathrm{CE}$ because the enlarged scavenging area enhances the flow of in-cylinder fresh charge into exhaust ports and scavenge ports at the end of scavenging process. In general, the SE is similar although it is improved slightly when SPO is fixed at $122{ }^{\circ} \mathrm{CA}$. It is noted the swirl motion is deteriorated with the increased SPH by comparing Fig. 23 and 26 because of the enlarged scavenging area.

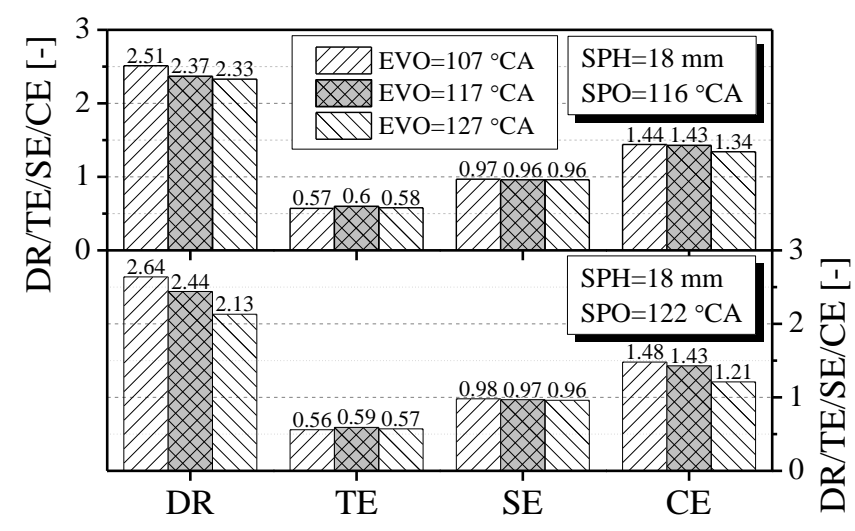

Figure 25. Effect of SPO and EVO on DR, TE, SE and CE (SPH=18mm, $2000 \mathrm{rpm}, \mathrm{P}_{\mathrm{i}}=2$ bar, fired condition). 


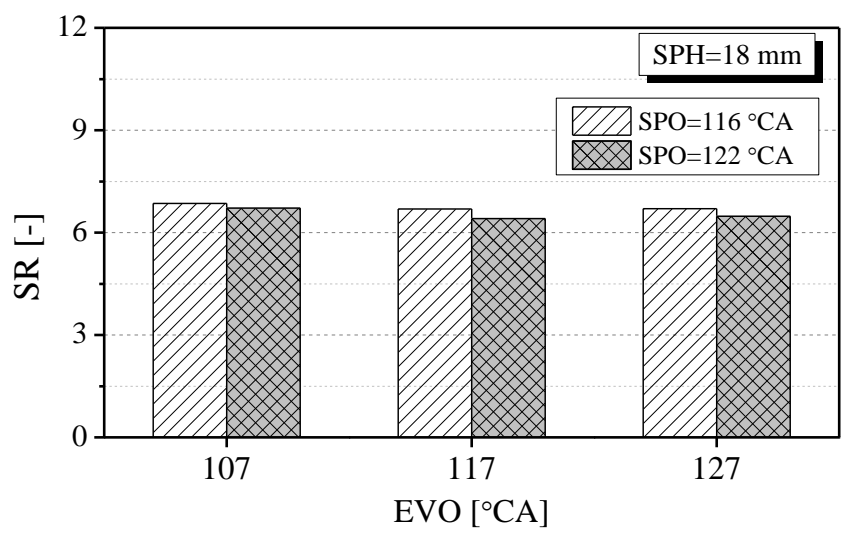

Figure 26. Effect of SPO and EVO on DR, TE, SE and CE (SPH=18mm, $2000 \mathrm{rpm}, \mathrm{P}_{\mathrm{i}}=2$ bar, fired condition).

\section{Conclusions}

In this study, 3D CFD simulations were adopted to evaluate different scavenge port designs for a boosted uniflow scavenged direct injection gasoline (BUSDIG) engine. Several important design parameters, e.g. scavenge port number (SPN), axis inclination angle (AIA), swirl orientation angle (SOA), scavenge port opening (SPO) timing, scavenge port height (SPH), were investigated in detail under different engine speeds and intake pressures $\left(\mathrm{P}_{\mathrm{i}}\right)$. The exhaust valve opening (EVO) timing was adjusted to match with scavenge port opening timing to obtain maximum scavenging performance. In order to obtain more realistic scavenging process, both cold and fired incylinder conditions were used to perform the CFD simulations. The study of grid sensitivity and cycle convergence was carried out to ensure the accuracy of the simulations. The findings are summarized as follows:

1. The increase in the absolute scavenging duration at low engine speeds leads to significantly higher DR and SE. As the engine speed increases, the DR and SE gradually reduce. The CE is similar under different engine speeds but shows a slightly higher value at the engine speed of $2000 \mathrm{rpm}$.

2. As the scavenge port number (SPN) is increased from 6 to 12 , the overall scavenging performance is increased. The maximum percentage changes of DR, TE, SE and $\mathrm{CE}$ under different engine speed and intake pressures are $9.6 \%, 5.8 \%, 8.0 \%$ and $12 \%$. But the increased SPN causes significant reduction in the swirl motion but has little impact on the tumble motion.

3. The CE and SE are improved with a bigger AIA because of the increased effective flow area. The swirl flow motion peaks at AIA around $75^{\circ}$ because of the increased tangential velocity component and less interaction of the intake flow jets with piston.

4. The CE increases with the SOA decreasing from $45^{\circ}$ to $20^{\circ}$ because of the increased DR. The further decrease in the SOA leads to lower CE because of the increased short-circuiting of the fresh gas. As a result, the $\mathrm{SE}$ also peaks at $\mathrm{SOA}=20^{\circ}$. The SR shows strong correlations with SOA under both cold and fired conditions.

5. Compared to the baseline design, the scavenge port design with $\mathrm{AIA}=90^{\circ}$ and $\mathrm{SOA}=20^{\circ}$ shows higher $\mathrm{CE}$ and $\mathrm{SE}$ under both cold and fired conditions.

\section{Page 10 of 13}

6. The early EVO leads to higher DR, SE and CE, which is less significant with early SPO $\left(116^{\circ} \mathrm{CA}\right)$ but more significant with late SPO $\left(128{ }^{\circ} \mathrm{CA}\right)$. The SR shows a decreasing trend with the delayed EVO and SPO.

7. The same effective compression ratio (ECR) and expansion ratio (EER) can be obtained around 11 when the EVO is fixed at $117{ }^{\circ} \mathrm{CA}$ ATDC. The lower limit of ECR and EER is around 10.22, which is determined by the EVC and EVO respectively. A later SPO of 128 ${ }^{0} \mathrm{CA}$ can extend the higher limit of ECR or EEC to 11.98 compared to the SPO of $116{ }^{\circ} \mathrm{CA}$.

8. Compared to the SPH of $14 \mathrm{~mm}$, SPH of $18 \mathrm{~mm}$ causes only slight improvement in DR and CE with early EVOs. When EVO delays to $127{ }^{\circ} \mathrm{CA}$, the increase in the SPH leads to slight decrease of CE. With SPH of $18 \mathrm{~mm}$, the SE remains similar and is improved slightly when SPO is set at $122{ }^{\circ} \mathrm{CA}$. The swirl motion is deteriorated with the increased SPH because of the enlarged flow area.

\section{References}

1. Mattarelli E. and Rinaldini C. A. "Two-Stroke Gasoline Engines for Small-Medium Passenger Cars". SAE Technical Paper 201501-1284.

2. Zhang Y., Nora M. D. and Zhao H. "Comparison of Performance, Efficiency and Emissions between Gasoline and E85 in a TwoStroke Poppet Valve Engine with Lean Boost CAI Operation". SAE Technical Paper 2015-01-0827.

3. Nishida K., Sakuyama H. and Kimijima T. "Improvement of Fuel Economy Using a New Concept of Two-Stroke Gasoline Engine Applying Stratified-Charge Auto-Ignition". SAE Technical Paper 2009-28-0009.

4. Johnson J. and Den Braven K. R. "Comparison of Homogeneous, Stratified and High-Squish Stratified Combustion in a DirectInjected Two-Stroke Engine". SAE Technical Paper 2008-320030 .

5. Osborne R. J., Stokes J. and Lake T. H. et al. "Development of a Two-Stroke/Four-Stroke Switching Gasoline Engine - The 2/4SIGHT Concept". SAE Technical Paper 2005-01-1137.

6. Zhang Y., Zhao H. and Ojapah M. et al. "2-Stroke CAI Operation on a Poppet Valve DI Engine Fuelled with Gasoline and its Blends with Ethanol". SAE Technical Paper 2013-011674 .

7. Benajes J., Martin J. and Novella R. et al. "Analysis of the Load Effect on the Partially Premixed Combustion Concept in a 2Stroke HSDI Diesel Engine Fueled with Conventional Gasoline". SAE Technical Paper 2014-01-1291.

8. Andwari A. M., Aziz A. A. and Said M. F. M. et al. Experimental investigation of the influence of internal and external EGR on the combustion characteristics of a controlled auto-ignition two-stroke cycle engine. Applied Energy 2014; 134(0): 1 - 10 .

9. Rocchi S., Rossi R. and Musu E. et al. Computational study of a two-stroke direct-injection reactivity-controlled compression 
ignition engine. Proceedings of the Institution of Mechanical Engineers, Part D: Journal of Automobile Engineering 2014; 229(8): 980-991.

10. Benajes J., Novella R. and De Lima D. et al. Investigation on Multiple Injection Strategies for Gasoline PPC Operation in a Newly Designed 2-Stroke HSDI Compression Ignition Engine. SAE Int. J. Engines 2015; 8(2): 758-774.

11. Zhang Y. and Zhao H. Measurement of short-circuiting and its effect on the controlled autoignition or homogeneous charge compression ignition combustion in a two-stroke poppet valve engine. Proceedings of the Institution of Mechanical Engineers, Part D: Journal of Automobile Engineering 2012; 226(8): 11101118.

12. Hult J., Matlok S. and Mayer S. "Particle Image Velocimetry Measurements of Swirl and Scavenging in a Large Marine TwoStroke Diesel Engine". SAE Technical Paper 2014-01-1173.

13. Ingvorsen K. M., Meyer K. E. and Walther J. H. et al. Turbulent swirling flow in a dynamic model of a uniflow-scavenged twostroke engine. Experiments in Fluids 2014; 55(6):1-18.

14. Sigurdsson E., Ingvorsen K. M. and Jensen M. V. et al. Numerical analysis of the scavenge flow and convective heat transfer in large two-stroke marine diesel engines. Applied Energy 2014; 123(0): 37 - 46.

15. Andersen F. H., Hult J. and Nogenmyr K. et al. "CFD Analysis of the Scavenging Process in Marine Two-Stroke Diesel Engines". Proceedings of the ASME 2014 Internal Combustion Engine Division Fall Technical Conference, October 19-22, 2014, Columbus, IN, USA.

16. Mattarelli E., Rinaldini C. A. and Baldini P. "Modeling and Experimental Investigation of a 2-Stroke GDI Engine for Range Extender Applications". SAE Technical Paper 2014-01-1672.

17. Hori H. "Scavenging Flow Optimization of Two-Stroke Diesel Engine by Use of CFD". SAE Technical Paper 2000-01-0903.

18. Laget O., Ternel C. and Thiriot J. et al. Preliminary Design of a Two-Stroke Uniflow Diesel Engine for Passenger Car. SAE Int. J. Engines 2013; 6(1): 596-613.

19. Knoll R. "AVL Two-Stroke Diesel Engine". SAE Technical Paper 981038.

20. Abthoff J., Duvinage F. and Hardt T. et al. "The 2-Stroke DIDiesel Engine with Common Rail Injection for Passenger Car Application". SAE Technical Paper 981032.

21. Cantore G. and Mattarelli E. "A New Concept for UltraCompact Automotive HSDI Diesel Engines". SAE Technical Paper 2007-01-1253.

22. Cd-adapco. "Methodology, STAR-CD VERSION 4.14, 2010".

23. Ma J., Zhao H. and Freeland P. et al. "Numerical Analysis of a Downsized 2-Stroke Uniflow Engine". SAE Technical Paper 2014-01-9051.

Page 11 of 13
24. Wang X., Xie H. and Zhao H. Computational study of the influence of in-cylinder flow on spark ignition-controlled autoignition hybrid combustion in a gasoline engine. International Journal of Engine Research 2015; 16(5): 795-809.

\section{Contact Information}

Dr. Xinyan Wang

xinyan.wang@brunel.ac.uk

Centre for Advanced Powertrain and Fuel Research

Brunel University London, UK

UB8 3PH

\section{Acknowledgments}

The authors gratefully acknowledge financial support by the Engineering and Physical Sciences Research Council (EPSRC).

\section{Definitions/Abbreviations}

\begin{tabular}{|c|c|}
\hline 3D & three-dimensional \\
\hline AIA & axis inclination angle \\
\hline ASI & arbitrary sliding interface \\
\hline BUSDIG & $\begin{array}{l}\text { boosted uniflow scavenged direct injection } \\
\text { gasoline }\end{array}$ \\
\hline $\mathbf{C E}$ & charging efficiency \\
\hline CFD & computational fluid dynamics \\
\hline CTR & cross tumble ratio \\
\hline DR & delivery ratio \\
\hline ECR & effective compression ratio \\
\hline ED & exhaust duration \\
\hline EER & effective expansion ratio \\
\hline EVC & exhaust valve close \\
\hline EVO & exhaust valve open \\
\hline IMEP & indicated mean effective pressure \\
\hline $\mathbf{P}_{\mathbf{i}}$ & intake pressure \\
\hline RGF & residual gas fraction \\
\hline RNG & re-normalisation group \\
\hline SE & scavenging efficiency \\
\hline SOA & swirl orientation angle \\
\hline SPC & scavenge port closing \\
\hline SPH & scavenge port height \\
\hline SPN & scavenge port number \\
\hline SPO & scavenge port opening \\
\hline SR & swirl ratio \\
\hline TDC & top dead center \\
\hline TE & trapping efficiency \\
\hline TR & tumble ratio \\
\hline VVT & variable valve timing \\
\hline
\end{tabular}




\section{Appendix}

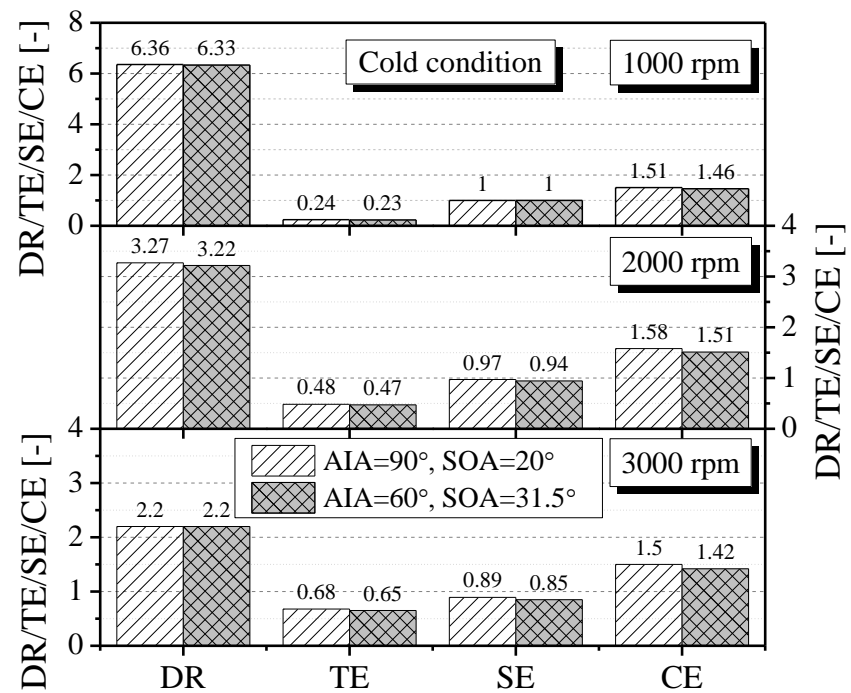

Figure A1. Comparison of DR, TE, SE and CE with different scavenge port designs and engine speeds $\left(\mathrm{P}_{\mathrm{i}}=2\right.$ bar, cold condition).

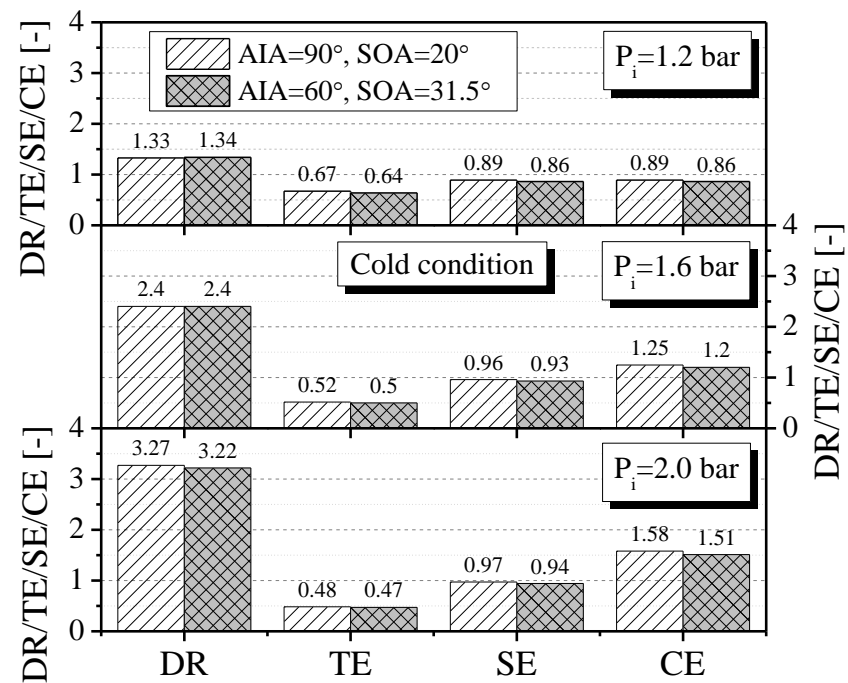

Figure A2. Comparison of DR, TE, SE and CE with different scavenge port designs and intake pressures (2000 rpm, cold condition).

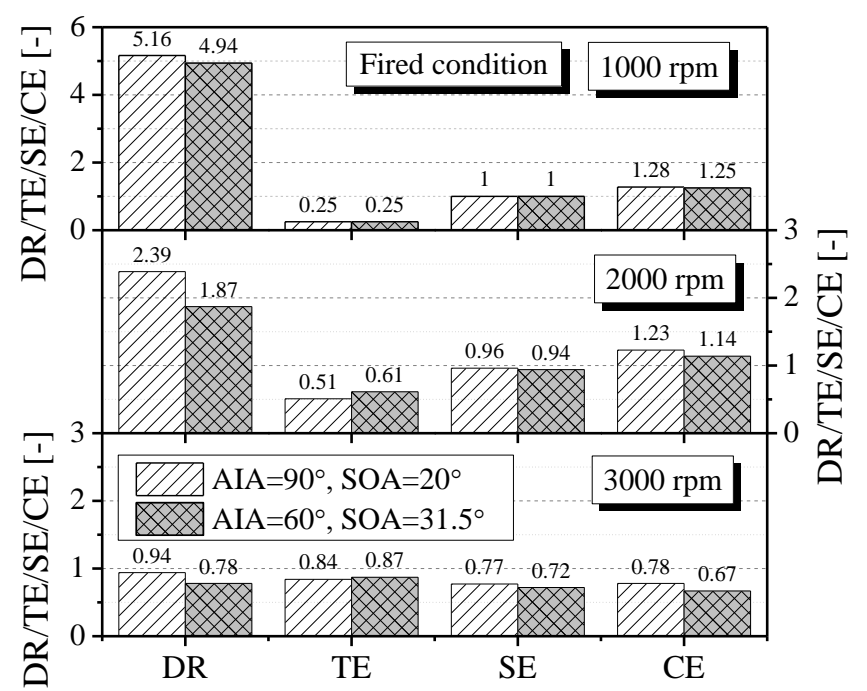

Figure A3. Comparison of DR, TE, SE and CE with different scavenge port designs and engine speeds $\left(\mathrm{P}_{\mathrm{i}}=2\right.$ bar, fired condition $)$.

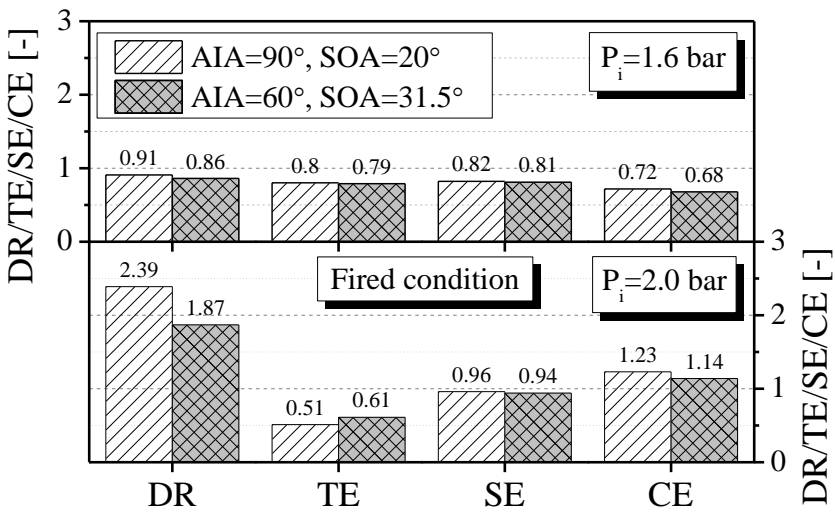

Figure A4. Comparison of DR, TE, SE and CE with different scavenge port designs and intake pressures (2000 rpm, fired condition). The results with $\mathrm{P}_{\mathrm{i}}=1.2$ bar are extremely low (DR, SE and $\left.\mathrm{CE}<0.1\right)$ and not shown in this figure.

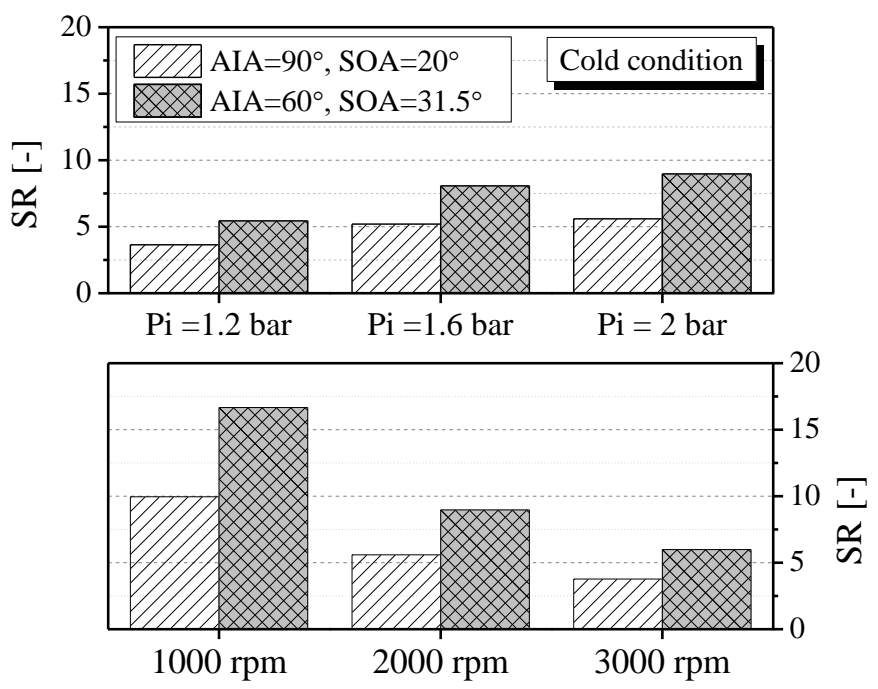

Figure A5. Comparison of SR at $280{ }^{\circ} \mathrm{CA}$ with different scavenge port designs, intake pressures and engine speeds (cold condition). 


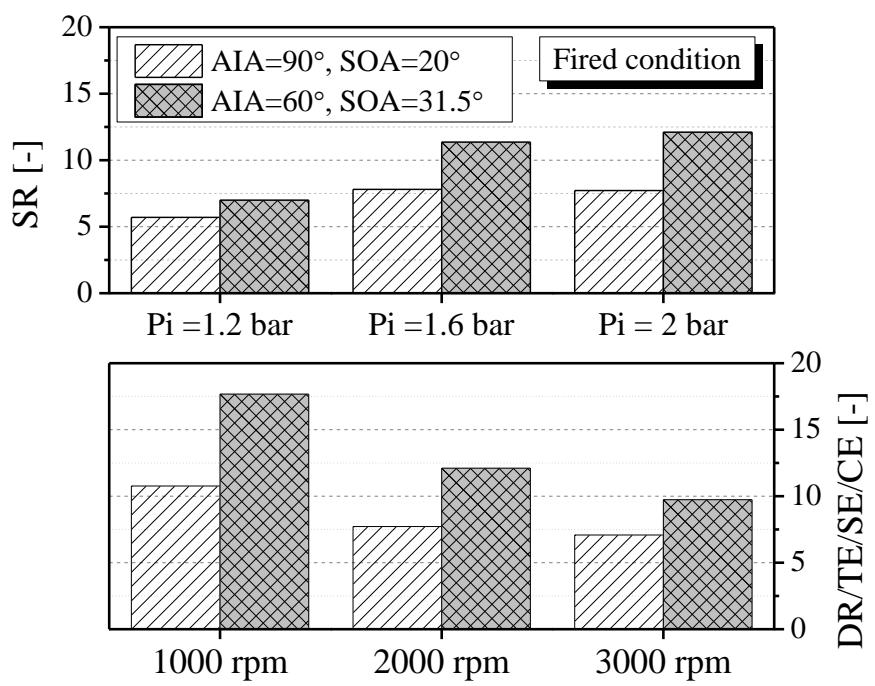

Figure A6. Comparison of SR at $280{ }^{\circ} \mathrm{CA}$ with different scavenge port designs, intake pressures and engine speeds (fired condition). 